\title{
Medical Radioisotope Production in a Power-Flattened ADS Fuelled with Uranium and Plutonium Dioxides
}

\author{
Gizem Bakır, ${ }^{1}$ Saltuk Buğra Selçuklu, ${ }^{2}$ and Hüseyin Yapıcı ${ }^{2}$ \\ ${ }^{1}$ Cumhuriyet Üniversitesi Teknoloji Fakültesi, 58140 Sivas, Turkey \\ ${ }^{2}$ Erciyes Üniversitesi Mühendislik Fakültesi, 38039 Kayseri, Turkey \\ Correspondence should be addressed to Hüseyin Yapıcı; yapici@erciyes.edu.tr
}

Received 22 February 2016; Revised 6 April 2016; Accepted 10 April 2016

Academic Editor: Arkady Serikov

Copyright (C) 2016 Gizem Bakır et al. This is an open access article distributed under the Creative Commons Attribution License, which permits unrestricted use, distribution, and reproduction in any medium, provided the original work is properly cited.

\begin{abstract}
This study presents the medical radioisotope production performance of a conceptual accelerator driven system (ADS). Leadbismuth eutectic (LBE) is selected as target material. The subcritical fuel core is conceptually divided into ten equidistant subzones. The ceramic (natural $\mathrm{U}, \mathrm{Pu})_{2}$ fuel mixture and the materials used for radioisotope production (copper, gold, cobalt, holmium, rhenium, thulium, mercury, palladium, thallium, molybdenum, and yttrium) are separately prepared as cylindrical rods cladded with carbon/carbon composite $(\mathrm{C} / \mathrm{C})$ and these rods are located in the subzones. In order to obtain the flattened power density, percentages of $\mathrm{PuO}_{2}$ in the mixture of $\mathrm{UO}_{2}$ and $\mathrm{PuO}_{2}$ in the subzones are adjusted in radial direction of the fuel zone. Timedependent calculations are performed at $1000 \mathrm{MW}$ thermal fission power $\left(P_{\mathrm{th}}\right)$ for one hour using the BURN card. The neutronic results show that the investigated ADS has a high neutronic capability, in terms of medical radioisotope productions, spent fuel transmutation and energy multiplication. Moreover, a good quasiuniform power density is achieved in each material case. The peak-to-average fission power density ratio is in the range of 1.02-1.28.
\end{abstract}

\section{Introduction}

Medical radioisotopes are used for the diagnosis and treatment of several illnesses. Radioisotopes can be produced in cyclotrons, nuclear reactors, or radioisotope generators. Accelerator driven systems (ADSs) can also be used for production of radioisotopes as well as fissile fuel breeding and energy generation. ADSs operate in subcritical mode; therefore, they are safer than conventional reactors which operate in critical mode. Large numbers of high energetic spallation neutrons can be produced in ADSs by means of target bombarding. Furthermore, these neutrons multiply in subcritical fuel core via fission reactions. For example, in Europe, MYRRHA (Multipurpose Hybrid Research Reactor for High-Tech Applications) is currently being studied. MYRRHA can produce neutron-rich radioisotopes due to its neutron flux characteristics [1]. ADSs can also be used for transmutation of nuclear wastes. Transmutation of the ${ }^{99} \mathrm{Tc}$, ${ }^{129} \mathrm{I}$, and ${ }^{135} \mathrm{Cs}$ isotopes is studied in our previous work [2]. This study investigates production potentials of some medical radioisotopes in a conceptual cylindrical leadbismuth eutectic (LBE) accelerator driven system (ADS) via neutron-gamma reactions.

Various methods of medical radioisotope production are studied by many researchers. Starovoitova et al. [3] investigate medical radioisotope production with photoneutron and photoproton reactions in linear accelerators. They consider ${ }^{100} \mathrm{Mo}(\gamma, \mathrm{n}){ }^{99} \mathrm{Mo}$ and ${ }^{68} \mathrm{Zn}(\gamma, \mathrm{p}){ }^{67} \mathrm{Cu}$ photonuclear capture reactions and compare results of Monte Carlo simulations with experimental data obtained with an electron accelerator. Richards et al. [4] examine the production of ${ }^{99 \mathrm{~m}} \mathrm{Tc}$ from ${ }^{100} \mathrm{Mo}_{2} \mathrm{C}$ targets in a medical cyclotron accelerator. Webster et al. [5] study the production of ${ }^{89} \mathrm{Y}(\mathrm{p}, \mathrm{n}){ }^{89} \mathrm{Zr},{ }^{64} \mathrm{Ni}(\mathrm{p}, \mathrm{n}){ }^{64} \mathrm{Cu}$, and ${ }^{103} \mathrm{Rh}(\mathrm{p}, \mathrm{n}){ }^{103} \mathrm{Pd}$ reactions in a compact and low energy accelerator system. They suggest that the considered accelerator system has sufficient production quantities for the medical applications and this system can be used for production of many other medical isotopes. Abbas et al. [6] develop an accelerator driven neutron activator based on 
a modified version of the Adiabatic Resonance Crossing (ARC) concept for medical radioisotope production. Kin et al. [7] study new production routes for copper isotopes $\left({ }^{64} \mathrm{Zn}(\mathrm{n}, \mathrm{p}){ }^{64} \mathrm{Cu},{ }^{67} \mathrm{Zn}(\mathrm{n}, \mathrm{p}){ }^{67} \mathrm{Cu}\right.$, and $\left.{ }^{68} \mathrm{Zn}(\mathrm{n}, \mathrm{x}){ }^{67} \mathrm{Cu}\right)$ by using accelerator neutrons and claim that ${ }^{64} \mathrm{Zn}(\mathrm{n}, \mathrm{p}){ }^{64} \mathrm{Cu}$ reaction is an encouraging route to produce ${ }^{64} \mathrm{Cu}$. Tárkányi et al. [811] examine the production of the therapeutic radioisotopes ${ }^{165} \mathrm{Er},{ }^{169} \mathrm{Yb}$, and ${ }^{166 \mathrm{~g}} \mathrm{Ho}$. Tárkányi et al. [12] later report new cross sections for ${ }^{197} \mathrm{Au}(\mathrm{d}, \mathrm{xn}){ }^{197 \mathrm{~m}, 197 \mathrm{~g}, 195 \mathrm{~m}, 195 \mathrm{~g}, 193 \mathrm{~m}, 193 \mathrm{~g}} \mathrm{Hg}$ and ${ }^{197} \mathrm{Au}(\mathrm{d}, \mathrm{x}){ }^{198 \mathrm{~m}, 198 \mathrm{~g}, 196 \mathrm{~m}, 196 \mathrm{~g}, 195,194 \mathrm{Au} \text { nuclear reactions }}$ and discuss the production of the medically relevant isotopes ${ }^{198} \mathrm{Au}$ and ${ }^{195 \mathrm{~m}, 195 \mathrm{~g}, 197 \mathrm{~m}, 197 \mathrm{~g}} \mathrm{Hg}$. They also provide the comparison with other charged particle induced production routes and the possible use of the ${ }^{197} \mathrm{Au}(\mathrm{d}, \mathrm{x}){ }^{197 \mathrm{~m}, 197 \mathrm{~g}, 195 \mathrm{~m}, 193 \mathrm{~m}} \mathrm{Hg}$ and ${ }^{196 m, 196 g} \mathrm{Au}$ reactions for monitoring deuteron beam parameters. Liem et al. [13] propose a conceptual design of a homogeneous solution reactor for production of ${ }^{99} \mathrm{Mo} /{ }^{99 \mathrm{~m}} \mathrm{Tc}$ medical radioisotope. Lebedev et al. [14] consider possible ways for production of ${ }^{173} \mathrm{Lu}$ and usages of other radioactive nuclides as radiation sources for crack detectors in gamma defectoscopes. Artun and Aytekin [15] calculate the excitation functions for production of medical radioisotopes ${ }^{122-125} \mathrm{I}$ with proton, alpha, and deuteron induced reactions. Nortier et al. [16] measure integral excitation functions for the production of 16 radioisotopes of $\mathrm{Cs}, \mathrm{Xe}$, and $\mathrm{I}$ in the bombardment of ${ }^{\text {nat }} \mathrm{Xe}$ with protons up to $100 \mathrm{MeV}$. Okuducu et al. [17] compute the nuclear level density parameters of some deformed radioisotopes of target nuclei (W, Hg) utilized on an ADS.

Power flattening can help in cooling of fuel core and reduce material stresses in an ADS because the nonuniform fission power density is the main cause of temperature and radiation damage gradients. Yapıcı and Übeyli [18] examine power flattening of the DT driven blanket in the Prometheus$\mathrm{H}$ (heavy ion) breeder reactor cooled with helium and fuelled with different mixed fuels (UC-ThC, $\mathrm{UO}_{2}-\mathrm{ThO}_{2}, \mathrm{UC}-\mathrm{C}$, $\mathrm{UO}_{2}-\mathrm{C}$, and $\left.{ }^{244} \mathrm{CmO}_{2}-\mathrm{UO}_{2}\right)$ and nuclear waste actinide. Their calculations show that the breeder reactor has high neutronic performance and can produce significant amount of energy, fissile fuel, and tritium required for $(\mathrm{D}, \mathrm{T})$ fusion reaction. Yapic1 [19] also investigates the neutronic performance of a blanket-driven ICF (inertial confinement fusion) neutron and based on $\mathrm{SiCf} / \mathrm{SiC}$ composite material for fissile fuel breeding and a flat fission power density. The blanket is loaded with $\mathrm{ThO}_{2}$ and $\mathrm{UO}_{2}$ mixed by various mixing methods to achieve a flat fission power density and cooled with natural lithium, $(\mathrm{LiF})_{2} \mathrm{BeF}_{2}, \mathrm{Li}_{17} \mathrm{~Pb}_{83}$, and ${ }^{4} \mathrm{He}$ for the nuclear heat transfer. Peek-to-average fission power density ratio $(\Gamma)$ of the blanket is reduced to $\sim 1.1$ which is expected to be reduced to $\sim 1.00$ to obtain a uniform fission power density profile. Yapıc1 [20] considers the transmutation of transuranium (TRU) discharged from PWR spent fuel and the possibility of a flat fission power (FFP) generation along the transmutation process in the force-free helical reactor (FFHR). In this study, potential of a conceptual cylindrical proton accelerator driven system (ADS) fuelled with mixture of ceramic $(\mathrm{U}, \mathrm{Pu}) \mathrm{O}_{2}$ is investigated for medical radioisotope production as well as production of fissile fuel and energy. The paper is organized as follows. In Section 2, the computational model of a conceptual accelerator driven system is explained. Calculation procedure is outlined in Section 3. Numerical results and conclusions are presented in Sections 4 and 5, respectively.

\section{Computational Model of Conceptual Accelerator Driven System}

The geometric model of the considered ADS is plotted in Figure 1(a). Linear accelerator (LINAC) is used as proton accelerator. The proton acceleration process consists of a $50 \mathrm{keV}$ Ion Source (IS), a $3 \mathrm{MeV}$ Radio Frequency Quadrupole (RFQ), a $40 \mathrm{MeV}$ Drift Tube LINAC (DTL), a $100 \mathrm{MeV}$ Cavity Coupled DTL (CCDTL), and superconducting linear accelerator (SC LINAC) to accelerate the beam to $1 \mathrm{GeV}$. As is apparent from Figure 1(a), the considered ADS contains four different zones: (i) spallation neutron target (SNT), (ii) subcritical core (SC), (iii) reflector zone (RZ), and (iv) shielding zone (SZ). The densities of used materials in the investigated ADS are given in Table 1. Furthermore, the power of the considered ADS is flattened by varying $\mathrm{PuO}_{2}$ percentage in the mixture throughout the subcritical core.

(i) Spallation Neutron Target. This zone includes liquid lead- (Pb-) bismuth (Bi) eutectic (LBE: 44.5\% Pb-55.5\% Bi eutectic). Although there are many materials in literature as target material, the LBE is still the most attractive for ADS designs because of its good neutronic, chemical, and thermal properties. The SNT is bombarded with high energetic proton particles, which in turn releases a few tens of high-energy spallation neutrons depending on the energy of proton. These neutrons diffuse through the SC to make transmutation and breeding reactions. In LBE targets, ${ }^{210} \mathrm{Po}$, which is an alpha emitter, is produced. The accelerator components must be isolated to prevent contamination of ${ }^{210} \mathrm{Po}$ and other possible radioactive wastes [21].

(ii) Subcritical Core. The ceramic (natural $\mathrm{U}, \mathrm{Pu}) \mathrm{O}_{2}$ fuel mixture and the materials used for radioisotope production (copper, gold, cobalt, holmium, rhenium, thulium, mercury, palladium, thallium, molybdenum, and yttrium) are separately prepared as cylindrical rods cladded with carbon/carbon composite (see Table 1). The considered $\mathrm{PuO}_{2}$ is extracted from PWR-MOX spent fuel (Manson et al. [22], fuel with plutonium recycle, $1000 \mathrm{MWe}$ reactor, $80 \%$ capacity factor, $33 \mathrm{MWd} / \mathrm{kg}$, and $32.5 \%$ thermal efficiency, 150 days after discharge). In order to achieve a flattened core power, the subcritical core is radially divided into ten equidistant subzones (these subzones are shown in Figure 1(a) as dashed lines) and the percentages of $\mathrm{PuO}_{2}$ in the fuel mixture are varied in each subzone. Nonetheless, the volumetric fractions (VFs) are kept the same. The cylindrical rods containing either the fuel or the materials are separately placed in the subzones of the subcritical fuel core in hexagonal order as shown in Figure 1(b) (for every 12 rods, 5 of them are fuel rods and 7 of them are material rods used for radioisotope production). Light water is used as the core coolant and it also 




(a)



(b)

FIGURE 1: (a) Cross-sectional view of the investigated ADS (1) SNT: spallation neutron target, (2) SCZ: subcritical core zone (divided into ten equidistant subzones), (3) RZ: reflector zone, and (4) SZ: shielding zone; dimensions are in cm). (b) Top cross-sectional view of sample two hexagonal arrangements of the fuel mixture rods (shaded) and the material rods used for the radioisotope production in the subcritical core zone (inner and outer radiuses $\left(r_{i}\right.$ and $r_{o}$ ) of the rods are $0.51 \mathrm{~cm}$ and $0.55 \mathrm{~cm}$, resp., pitch length $P=1.2 \mathrm{~cm}$, and the volume fractions of fuel mixture (total 5 rods), materials used for isotope production (total 7 rods), clad, and coolant are 25\%, 35\%, 10\%, and 30\%, resp; the dimensions are not in scale).

serves as neutron moderator. According to the dimensions and arrangements of the rods, the VFs of the fuel mixture, the materials used for radioisotope production, the clad, and the coolant are calculated as $25 \%, 35 \%, 10 \%$, and $30 \%$, respectively.

(iii) Reflector Zone. The function of this zone is to reflect the neutrons escaping from the SC zone to enhance transmutation reactions. Therefore, graphite (carbon) is selected as a reflective material due to the fact that its scatter cross section is much greater than its absorption cross section. Moreover, the graphite is a good neutron moderator and it also has a high-temperature-resistance property. The graphite is widely used in nuclear implementation as an effective neutron reflector and moderator.

(iv) Shielding Zone. The role of this last zone made of boron carbide $\left(\mathrm{B}_{4} \mathrm{C}\right)$, which has a very high absorption cross section and excellent thermomechanical properties, is to absorb the neutrons leaking from the $\mathrm{RZ} . \mathrm{B}_{4} \mathrm{C}$ is usually preferred in nuclear reactors as a neutron absorber.

\section{Calculation Procedure}

The neutronic computations have been carried out with the high-energy Monte Carlo code MCNPX 2.7 [23] by using the LA150 library [24]. "The library consists of evaluated reaction cross-sections and emission spectra up to $150 \mathrm{MeV}$ for incident neutrons and protons, for over 40 target isotopes important in the SNTs, structural materials, and shielding" [2]. Bertini INC model [25] is used for the intranuclear cascade of spallation reactions. Time-dependent calculations have been performed at $1000 \mathrm{MW}$ thermal fission power $\left(P_{\mathrm{th}}\right)$ for one hour using the BURN card option of the MCNPX2.7 code [23]. The burn cycle times are considered as one hour in all cases due to the fact that the produced medical isotopes have short half-lives.

In the literature and our previous studies $[2,26]$, it is found that the gain $(G)$ reaches the maximum value when proton energy $\left(E_{p}\right)$ is $1000 \mathrm{MeV}$. Hence, energy of one source proton is assumed as $1000 \mathrm{MeV}$ in this study (see Figure 1(a)). A continuous uniform proton source bombards on the target material and the source radius is $4 \mathrm{~cm}$.

\section{Numerical Results}

4.1. Neutron Flux. The spatial variations of neutron fluxes in the case of copper and in the case of copper and thulium are plotted in Figure 2. Generally, it is observed that the fluxes of neutrons, which are produced with spallation and fission reactions, decrease by deeper penetration in the target and subcritical zones. In particular, the number of neutrons having energy of less than $2-4 \mathrm{MeV}$ decreases due to collisions with hydrogen and other atoms in the subcritical zones.

4.2. Flattened Fission Power Density. The fuel zone of an ADS is a region containing highly energetic spallation and fission neutrons. The fission power density in this zone decreases exponentially from inner side to outer side in radial direction due to the decrease of neutron fluxes. Therefore, 
TABLE 1: Isotopic fractions and densities of the materials used in the investigated ADS.

\begin{tabular}{|c|c|c|c|}
\hline Material & Density $\left[\mathrm{g} / \mathrm{cm}^{3}\right]$ & Nuclide & Fraction [\%] \\
\hline \multirow{2}{*}{$\mathrm{LBE}$} & 11.344 & $\mathrm{~Pb}$ & 44.5 \\
\hline & 9.80 & $\mathrm{Bi}$ & 55.5 \\
\hline $\mathrm{H}_{2} \mathrm{O}$ & 1.00 & - & 100 \\
\hline $\mathrm{C} / \mathrm{C}$ & 1.85 & ${ }^{12} \mathrm{C}$ & 100 \\
\hline \multirow{2}{*}{$\mathrm{UO}_{2}$} & \multirow{2}{*}{10.54} & ${ }^{235} \mathrm{U}$ & 0.7 \\
\hline & & ${ }^{238} \mathrm{U}$ & 99.3 \\
\hline \multirow{5}{*}{$\mathrm{PuO}_{2}$} & \multirow{5}{*}{11.50} & ${ }^{238} \mathrm{Pu}$ & 3.53535 \\
\hline & & ${ }^{239} \mathrm{Pu}$ & 45.0154 \\
\hline & & ${ }^{240} \mathrm{Pu}$ & 26.3505 \\
\hline & & ${ }^{241} \mathrm{Pu}$ & 15.9640 \\
\hline & & ${ }^{242} \mathrm{Pu}$ & 9.13483 \\
\hline \multicolumn{4}{|c|}{ For radioisotope production } \\
\hline \multirow{2}{*}{$\mathrm{Cu}$} & \multirow{2}{*}{8.92} & ${ }^{63} \mathrm{Cu}$ & 68.499 \\
\hline & & ${ }^{65} \mathrm{Cu}$ & 31.501 \\
\hline $\mathrm{Au}$ & 18.880 & ${ }^{197} \mathrm{Au}$ & 100 \\
\hline Co & 8.900 & ${ }^{59} \mathrm{Co}$ & 100 \\
\hline Ho & 8.795 & ${ }^{165} \mathrm{Ho}$ & 100 \\
\hline \multirow{2}{*}{$\operatorname{Re}$} & \multirow{2}{*}{20.530} & ${ }^{185} \operatorname{Re}$ & 37.148 \\
\hline & & ${ }^{187} \mathrm{Re}$ & 62.852 \\
\hline $\mathrm{Tm}$ & 9.321 & ${ }^{169} \mathrm{Tm}$ & 100 \\
\hline \multirow{7}{*}{$\mathrm{Hg}$} & \multirow{7}{*}{13.546} & ${ }^{196} \mathrm{Hg}$ & 14.6 \\
\hline & & ${ }^{198} \mathrm{Hg}$ & 9.869 \\
\hline & & ${ }^{199} \mathrm{Hg}$ & 16.763 \\
\hline & & ${ }^{200} \mathrm{Hg}$ & 23.028 \\
\hline & & ${ }^{201} \mathrm{Hg}$ & 13.225 \\
\hline & & ${ }^{202} \mathrm{Hg}$ & 30.004 \\
\hline & & ${ }^{204} \mathrm{Hg}$ & 6.965 \\
\hline \multirow{6}{*}{$\mathrm{Pd}$} & \multirow{6}{*}{12.02} & ${ }^{102} \mathrm{Pd}$ & 0.977 \\
\hline & & ${ }^{104} \mathrm{Pd}$ & 10.877 \\
\hline & & ${ }^{105} \mathrm{Pd}$ & 22.013 \\
\hline & & ${ }^{106} \mathrm{Pd}$ & 27.199 \\
\hline & & ${ }^{109} \mathrm{Pd}$ & 26.830 \\
\hline & & ${ }^{110} \mathrm{Pd}$ & 12.104 \\
\hline \multirow{2}{*}{$\mathrm{Tl}$} & \multirow{2}{*}{11.850} & ${ }^{203} \mathrm{Tl}$ & 29.316 \\
\hline & & ${ }^{205} \mathrm{Tl}$ & 70.684 \\
\hline \multirow{7}{*}{ Mo } & \multirow{7}{*}{10.20} & ${ }^{92} \mathrm{Mo}$ & 14.230 \\
\hline & & ${ }^{94} \mathrm{Mo}$ & 9.053 \\
\hline & & ${ }^{95} \mathrm{Mo}$ & 15.748 \\
\hline & & ${ }^{96} \mathrm{Mo}$ & 16.673 \\
\hline & & ${ }^{97} \mathrm{Mo}$ & 9.646 \\
\hline & & ${ }^{98} \mathrm{Mo}$ & 24.623 \\
\hline & & ${ }^{100} \mathrm{Mo}$ & 10.028 \\
\hline $\mathrm{Y}$ & 4.469 & ${ }^{89} \mathrm{Y}$ & 100 \\
\hline Graphite & 2.10 & ${ }^{12} \mathrm{C}$ & 100 \\
\hline \multirow{2}{*}{$\mathrm{B}_{4} \mathrm{C}$} & \multirow{2}{*}{2.52} & ${ }^{10} \mathrm{~B}$ & 18.431 \\
\hline & & ${ }^{11} \mathrm{~B}$ & 81.569 \\
\hline
\end{tabular}



(a)



(b)

FIGURE 2: Neutron fluxes [SCZ $=$ subcritical zone, energy $=\left(E_{i+1}-\right.$ $\left.E_{i}\right) /$ Lethargy, and Lethargy $\left.=\ln \left(E_{i+1} / E_{i}\right)\right]$.

the fission power density in an ADS is nonuniform in radial direction. The nonuniform fission power density is the main cause of temperature and radiation damage gradients. This characteristic is generally observed in fast ADS and similar power systems. On the other hand, a flattened fission power density would help in cooling of fuel core and reduce material stresses. The peak-to-average fission power density ratio $(\Gamma)$ is a measure of fission power density uniformity. To obtain a uniform fission power density profile, this ratio must be reduced to $\sim 1.00$. In this study, in order to obtain the flattened power density, percentages of $\mathrm{PuO}_{2}$ in the mixture of $\mathrm{UO}_{2}$ and $\mathrm{PuO}_{2}$ in the subzones are adjusted in radial direction of the fuel zone (see Table 2). All values of $\Gamma$ in all investigated 


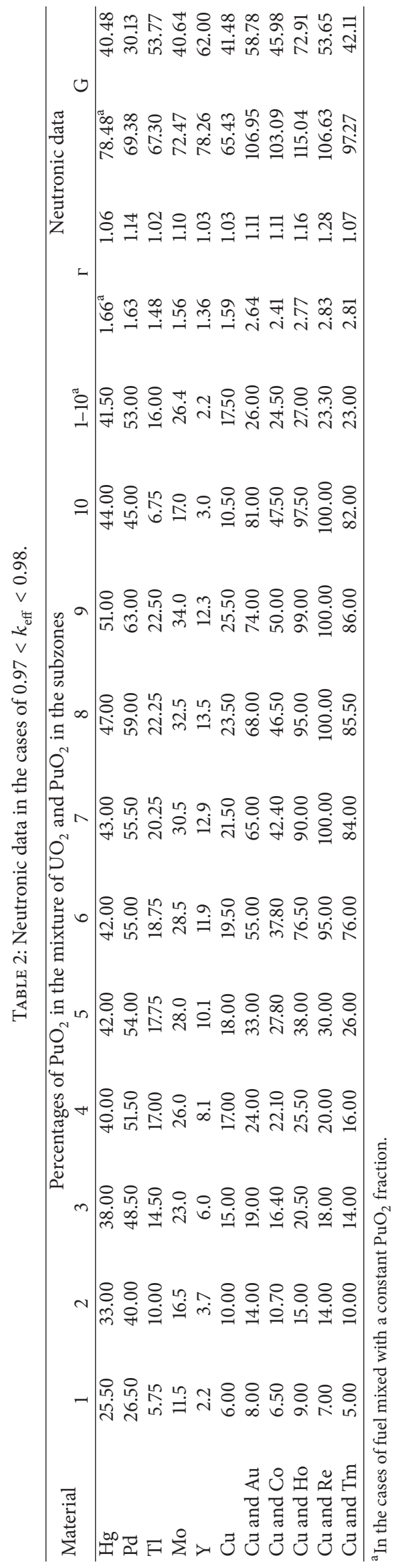


cases are also given in Table 2. Values of $\Gamma$ vary in the range of 1.02-1.28. The best uniformity is acquired in the case of thallium $(\Gamma=1.02)$. These values when compared to the values of Yapıc1 and Übeyli [18] $(\Gamma=1.051-1.069)$ and Yap1c1 [19] $(\Gamma=$ 1.131-1.403) show that a good quasiuniform power density is achieved in each material case of this study.

Figure 3 shows variations of nonuniform and quasiuniform fission densities in the fuel core in the cases of mercury, palladium, thallium, molybdenum, and yttrium. As it is apparent from this figure, in the cases of constant $\mathrm{PuO}_{2}$ fraction in the fuel mixture, the fission power profiles decrease exponentially. However, these profiles increase toward the outer zone due to neutron reflection from the reflector zone. The profile of flattened fission power is lower than that of nonuniform fission power for all considered material cases and the highest flattened fission power profile is in the yttrium case (about $6.2 \cdot 10^{-5}$ fissions $/ \mathrm{cm}^{3}$ ).

In the cases of other considered materials (copper, gold, cobalt, holmium, rhenium, and thulium), the variations of nonuniform and quasiuniform fission densities in the fuel core are plotted in Figure 4. The first subplot of this figure shows the case where the copper rods are placed in all ten subzones. In other cases, the rods containing copper that has low capture cross section are placed into the first five subzones, and the rods including one of the other considered materials (gold, cobalt, holmium, rhenium, and thulium) having higher capture cross section than copper are located into the next five subzones. The reason that gold, cobalt, holmium, rhenium, and thulium are used with copper is to keep $k_{\text {eff }}$ in the range of $0.97-0.98$. Furthermore, for the same reason in the cases copper-rhenium and copper-thulium, the VFs of the fuel mixture and the materials have to be changed from $25 \%$ and $35 \%$ to $30 \%$ and $30 \%$, respectively. Similar to the cases shown in Figure 3, in the cases of constant $\mathrm{PuO}_{2}$ fraction in the fuel mixture, the fission power profiles decrease rapidly and the profile of flattened fission power is lower than that of nonuniform fission power for all considered material cases. The highest flattened fission power profile is in the copper-holmium case (about $7.4 \cdot 10^{-5}$ fissions $/ \mathrm{cm}^{3}$ ).

4.3. Gain. The energy gain, $G$, is the ratio of the total fission energy production in the fuel core to the energy of the proton beam and it is calculated as follows:

$$
G=\frac{R_{f} E_{f}}{E_{p}},
$$

where $R_{f}$ is the number of fission reactions and $E_{f}$ is the energy per fission $(200 \mathrm{MeV})$. The gain can also be calculated as

$$
G=\frac{P_{\text {th }}}{P E}
$$

where $P_{\text {th }}$ is the thermal power and it is assumed as $1000 \mathrm{MW}$, and $\mathrm{PE}$ is the proton beam power.

The energy gain is one of the most important outputs of an ADS and the gain values acquired in this study are given in Table 2. These results show that gain values of power-flattened case (30.13-72.91) are lower than the values of the case of fuel mixed with a constant $\mathrm{PuO}_{2}$ fraction (65.43-115.04). The highest gain values of both cases are reached when copperholmium is used:

$$
\mathrm{PE}=\frac{P_{\mathrm{th}}}{G} .
$$

The value of proton flux $(\mathrm{PF})$ varies in the ranges of $0.5 \cdot 10^{17}-0.96 \cdot 10^{17}$ protons $/ \mathrm{s}$ in the constant $\mathrm{PuO}_{2}$ fraction case and $0.86 \cdot 10^{17}-1.5 \cdot 10^{17}$ protons/s in the flattened power case, depending on the PE value. $10^{17}$ protons (having a $1000 \mathrm{MeV}$ of energy) per second correspond to a 16.02 MW of PE.

4.4. Medical Radioisotope Production. Medical radioisotopes are used for diagnosis, treatment, and therapy. Usage areas and production reactions of the radioisotopes considered in this study are shown in Table 3. Medical radioisotopes are generally produced artificially because most of the naturally found radioisotopes have long half-lives and they are mostly harmful for human body. Radioisotopes are usually produced in cyclotrons, nuclear reactors, or radioisotope generators depending on the target nucleus or energy of radiator particles. The conceptual system of this study is an accelerator driven system (ADS). A general radioisotope production reaction that takes place in an $\mathrm{ADS}$ is a neutron capture reaction as follows:

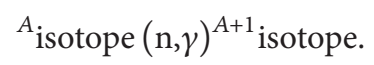

Activities of the radioisotopes of this study at the end of one hour for the cases of fuel mixed with a constant $\mathrm{PuO}_{2}$ fraction and the cases of flattened power are presented in Tables 4 and 5, respectively. Activities of produced radioisotopes are generally higher in the flattened power cases except for ${ }^{203} \mathrm{Hg}$ and ${ }^{103} \mathrm{Pd}$. The production of ${ }^{198} \mathrm{Au},{ }^{60} \mathrm{Co},{ }^{166} \mathrm{Ho},{ }^{186} \mathrm{Re}$, and ${ }^{170} \mathrm{Tm}$ increases almost threefold in the flattened power cases compared to the cases of fuel mixed with a constant $\mathrm{PuO}_{2}$ fraction. The reason of this increase is the adjustment of the $\mathrm{PuO}_{2}$ fraction in the fuel mixture; that is, the $\mathrm{PuO}_{2}$ fraction is decreased in the inner zones and increased in the outer zones in the flattened power cases (see Table 2). The production of other radioisotopes is almost the same in both cases. ${ }^{197} \mathrm{Au}$ production $(28.780 \mathrm{~g})$ is the highest and the lowest production is ${ }^{103} \mathrm{Pd}(0.192 \mathrm{~g})$ among all the considered radioisotopes. These values are quite high with respect to medical isotope production in low energy proton accelerators (75 MeV-150 MeV) because the ADSs are bombarded with high energetic protons $(\mathrm{PE}>500 \mathrm{MeV})$ and have a subcritical fuel core that also multiply neutrons.

\section{Conclusions}

A conceptual cylindrical ADS is examined for medical radioisotope production, spent fuel transmutation, and energy production. The main results of this study are given briefly as follows:

(i) A good quasiuniform power density is achieved in each material case ( $\Gamma$ is in the range 1.02-1.28). The 


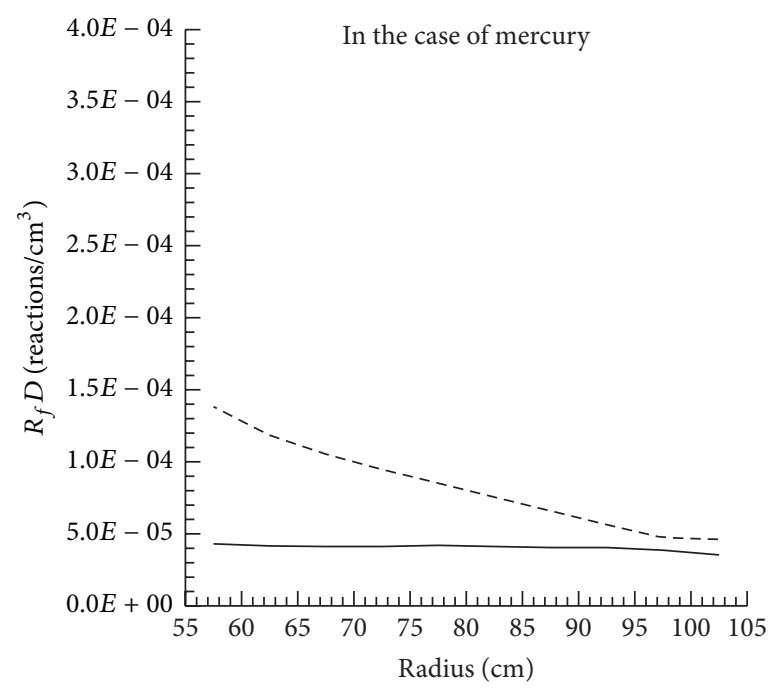

(a)

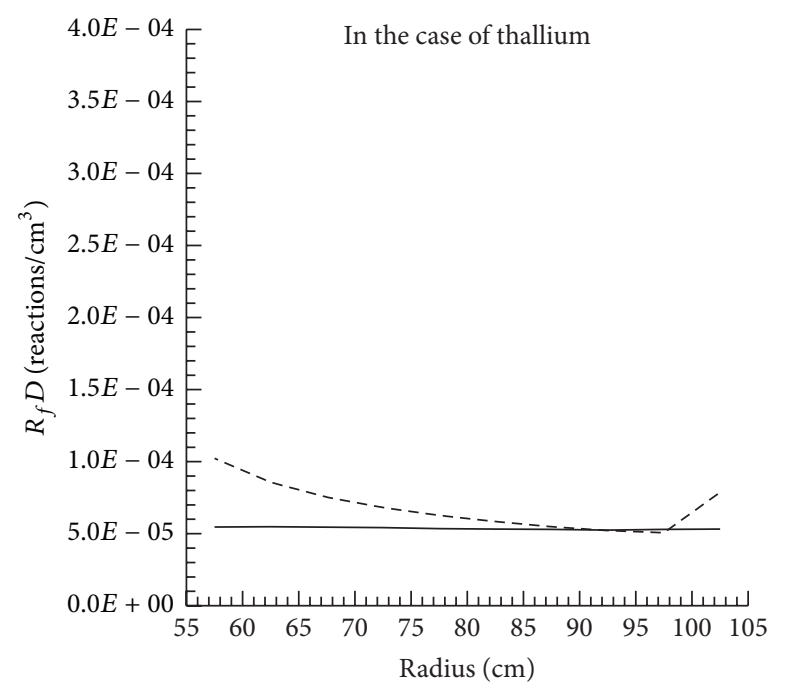

(c)



(b)



(d)

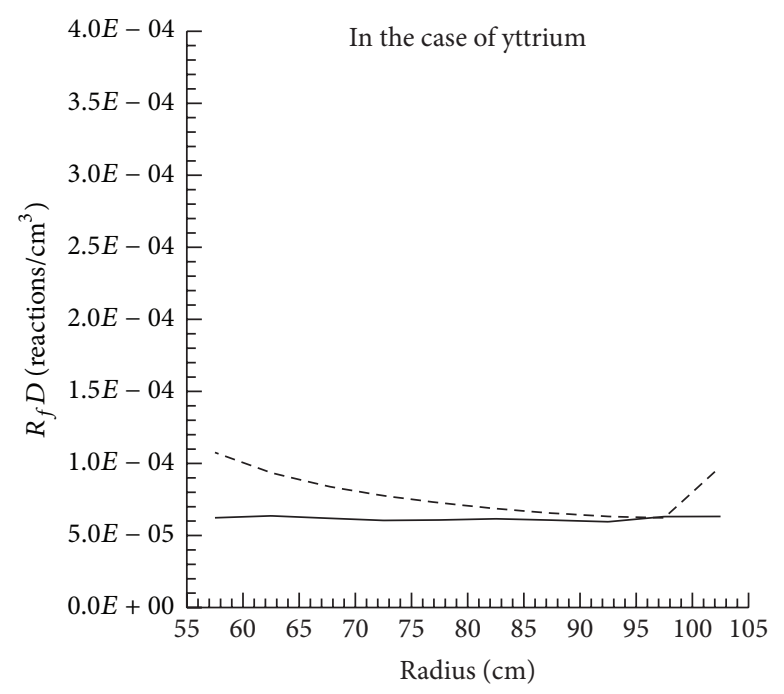

(e)

FIgURE 3: Variations of fission densities in the fuel core versus the core radius (solid line indicates the flattened power case). 


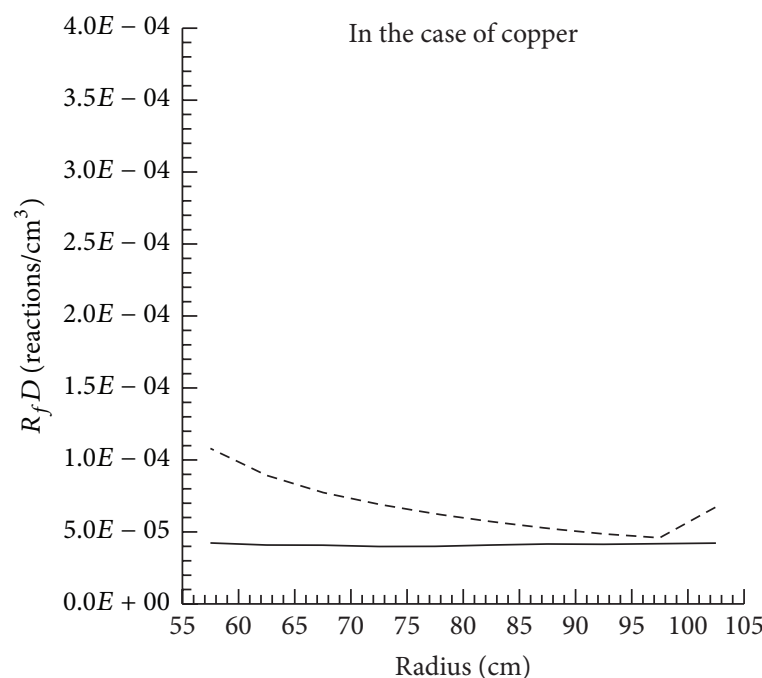

(a)

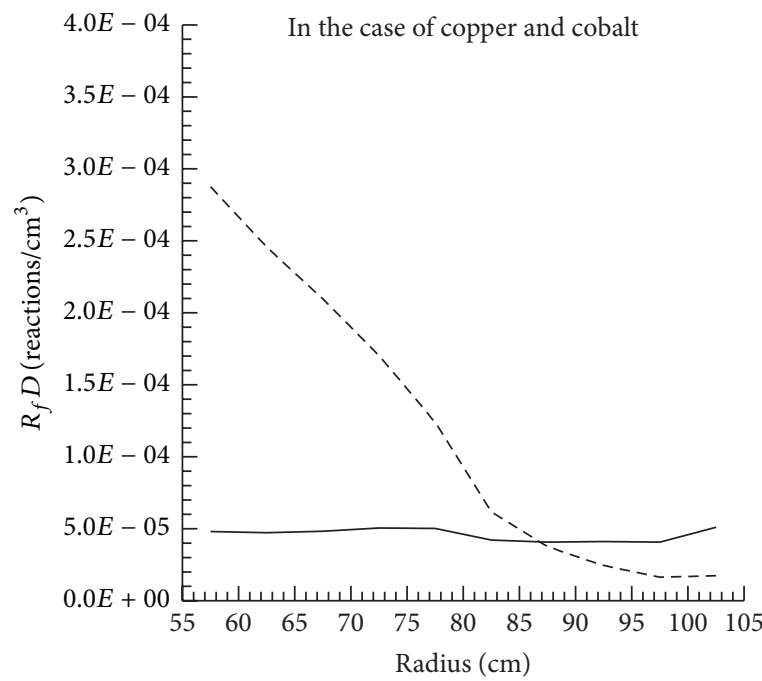

(c)



(e)



(b)

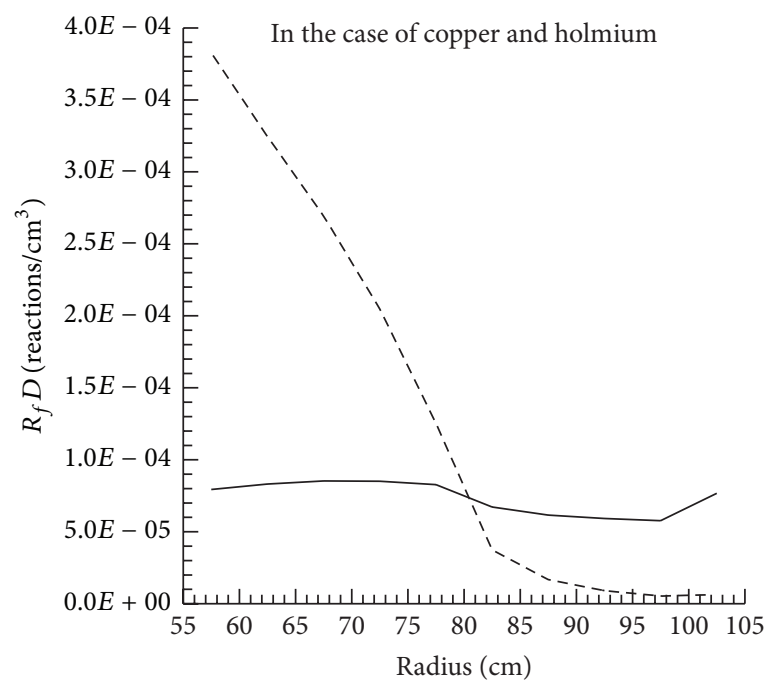

(d)



(f)

FIGURE 4: Variations of fission densities in the fuel core versus the core radius (solid line indicates the flattened power case). 
TABLE 3: Usage areas and reactions of the produced radioisotopes.

\begin{tabular}{|c|c|c|}
\hline Radioisotope & Half-life & Usage areas \\
\hline${ }^{63} \mathrm{Cu}$ & 12.7 hours & $\begin{array}{l}\text { Radiopharmaceuticals for PET (positron emission tomography) } \\
\text { imaging of cancer }\end{array}$ \\
\hline${ }^{198} \mathrm{Au}$ & 2.69 days & $\begin{array}{l}\text { Treatment of cancer of prostate and bladder } \\
\text { for reduction of fluid accumulation secondary to cancer }\end{array}$ \\
\hline $\begin{array}{l}{ }^{60} \mathrm{Co} \\
{ }^{59} \mathrm{Co}+\mathrm{n} \stackrel{\gamma}{\rightarrow}{ }^{60} \mathrm{Co}\end{array}$ & 5.27 years & Modern radiation therapy and industrial radiography \\
\hline $\begin{array}{l}{ }^{166} \mathrm{Ho} \\
{ }^{165} \mathrm{Ho}+\mathrm{n} \stackrel{\gamma}{\rightarrow}{ }^{166} \mathrm{Ho}\end{array}$ & 26.77 hours & $\begin{array}{l}\text { Medical radiotherapeutic applications, radioembolization for the } \\
\text { treatment of patients with liver metastases }\end{array}$ \\
\hline $\begin{array}{l}{ }^{170} \mathrm{Tm} \\
{ }^{169} \mathrm{Tm}+\mathrm{n} \stackrel{\gamma}{\rightarrow}{ }^{170} \mathrm{Tm}\end{array}$ & 128.6 days & X-ray source for cancer therapy with brachytherapy \\
\hline $\begin{array}{l}{ }^{186} \mathrm{Re} \\
{ }^{185} \mathrm{Re}+\mathrm{n} \stackrel{\gamma}{\rightarrow}{ }^{186} \mathrm{Re}\end{array}$ & 3.7183 days & Radiotherapy, bone pain palliation \\
\hline $\begin{array}{l}{ }^{197} \mathrm{Hg} \\
{ }^{196} \mathrm{Hg}+\mathrm{n} \stackrel{\gamma}{\rightarrow}{ }^{197} \mathrm{Hg}\end{array}$ & 64.128 hours & Scanning kidneys \\
\hline${ }^{102} \mathrm{Pd}+\mathrm{nd} \stackrel{\gamma}{\rightarrow}{ }^{103} \mathrm{Pd}$ & 16.991 days & Treatment of prostate cancer \\
\hline $\begin{array}{l}{ }^{204} \mathrm{Tl} \\
{ }^{203} \mathrm{Tl}+\mathrm{n} \stackrel{\gamma}{\rightarrow}{ }^{204} \mathrm{Tl}\end{array}$ & 3.78 years & Myocardial perfusion scans \\
\hline $\begin{array}{l}9{ }^{99} \mathrm{Mo} \\
{ }^{98} \mathrm{Mo}+\mathrm{n} \stackrel{\gamma}{\rightarrow}{ }^{99} \mathrm{Mo}\end{array}$ & 65.94 hours & ${ }^{99 \mathrm{~m}} \mathrm{Tc}$ generators \\
\hline $\begin{array}{l}{ }^{99 \mathrm{~m}} \mathrm{Tc} \\
{ }^{99} \mathrm{Mo} \rightarrow{ }^{99 \mathrm{~m}} \mathrm{Tc}+\beta^{-}+v_{e}\end{array}$ & 6 hours & $\begin{array}{l}\text { Imaging of the skeleton, heart muscle, brain, thyroid, lungs, liver, } \\
\text { spleen, kidney, gall bladder, bone marrow, salivary, lacrimal glands, } \\
\text { heart blood pool, and infection }\end{array}$ \\
\hline${ }^{90} \mathrm{Y}$ & 64.053 hours & $\begin{array}{l}\text { Cancer brachytherapy and as silicate colloid for the relieving of the } \\
\text { pain of arthritis in larger synovial joints. }\end{array}$ \\
\hline
\end{tabular}

TABLE 4: Activities of the radioisotopes at the end of one hour in the case of fuel mixed with a constant $\mathrm{PuO}_{2}$ fraction $\left(P_{\mathrm{th}}=1000 \mathrm{MW}\right)$.

\begin{tabular}{|c|c|c|c|}
\hline Materials & Isotopes & $\operatorname{Activity~(A)~[Ci]~}$ & Mass [g] \\
\hline $\mathrm{Cu}$ & 29064 & $8.229 E+06$ & 2.132 \\
\hline \multirow{2}{*}{$\mathrm{Cu}$ and $\mathrm{Au}$} & 29064 & $5.868 E+06$ & 1.520 \\
\hline & 79198 & $2.857 E+06$ & 11.680 \\
\hline \multirow{2}{*}{$\mathrm{Cu}$ and $\mathrm{Co}$} & 29064 & $5.581 E+06$ & 1.446 \\
\hline & 27060 & $3.127 E+03$ & 2.764 \\
\hline \multirow{2}{*}{$\mathrm{Cu}$ and $\mathrm{Ho}$} & 29064 & $5.978 E+06$ & 1.549 \\
\hline & 67166 & $6.782 E+06$ & 9.624 \\
\hline \multirow{3}{*}{$\mathrm{Cu}$ and $\mathrm{Re}$} & 29064 & $5.188 E+06$ & 1.344 \\
\hline & 75186 & $9.486 E+05$ & 5.102 \\
\hline & 75188 & $6.167 E+06$ & 6.281 \\
\hline \multirow{2}{*}{$\mathrm{Cu}$ and $\mathrm{Tm}$} & 29064 & $5.220 E+06$ & 1.353 \\
\hline & 69170 & $6.530 E+04$ & 10.930 \\
\hline \multirow{2}{*}{$\mathrm{Hg}$} & 80197 & $1.422 E+06$ & 5.728 \\
\hline & 80203 & $1.190 E+04$ & 0.862 \\
\hline \multirow{5}{*}{$\mathrm{Pd}$} & 46103 & $1.433 E+04$ & 0.192 \\
\hline & 46107 & $1.183 E-03$ & 2.300 \\
\hline & 46109 & $1.051 E+07$ & 5.002 \\
\hline & 46111 & $2.030 E+07$ & 0.280 \\
\hline & 46112 & $6.087 E+04$ & 0.046 \\
\hline \multirow{2}{*}{$\mathrm{Tl}$} & 81202 & $9.066 E+02$ & 0.017 \\
\hline & 81204 & $4.343 E+03$ & 9.366 \\
\hline Mo & 42099 & $1.075 E+06$ & 2.237 \\
\hline $\mathrm{Y}$ & 39090 & $3.402 E+05$ & 0.626 \\
\hline
\end{tabular}

TABLE 5: Activities of the radioisotopes at the end of one hour in the flattened power case $\left(P_{\text {th }}=1000 \mathrm{MW}\right)$.

\begin{tabular}{|c|c|c|c|}
\hline Materials & Isotopes & Activity [Ci] & Mass [g] \\
\hline $\mathrm{Cu}$ & 29064 & $8.574 E+06$ & 2.222 \\
\hline \multirow{2}{*}{$\mathrm{Cu}$ and $\mathrm{Au}$} & 29064 & $2.909 E+06$ & 0.754 \\
\hline & 79198 & $7.040 E+06$ & 28.780 \\
\hline \multirow{2}{*}{$\mathrm{Cu}$ and $\mathrm{Co}$} & 29064 & $2.809 E+06$ & 0.728 \\
\hline & 27060 & $6.662 E+03$ & 5.887 \\
\hline \multirow{2}{*}{$\mathrm{Cu}$ and $\mathrm{Ho}$} & 29064 & $2.930 E+06$ & 0.759 \\
\hline & 67166 & $1.809 E+07$ & 25.680 \\
\hline \multirow{3}{*}{$\mathrm{Cu}$ and $\mathrm{Re}$} & 29064 & $2.656 E+06$ & 0.688 \\
\hline & 75186 & $2.707 E+06$ & 14.560 \\
\hline & 75188 & $1.821 E+07$ & 18.550 \\
\hline \multirow{2}{*}{$\mathrm{Cu}$ and $\mathrm{Tm}$} & 29064 & $2.285 E+06$ & 0.592 \\
\hline & 69170 & $1.901 E+05$ & 31.810 \\
\hline \multirow{2}{*}{$\mathrm{Hg}$} & 80197 & $4.453 E+05$ & 5.912 \\
\hline & 80203 & $1.551 E+03$ & 0.850 \\
\hline \multirow{5}{*}{$\mathrm{Pd}$} & 46103 & $1.869 E+03$ & 0.192 \\
\hline & 46107 & $1.562 E-04$ & 2.298 \\
\hline & 46109 & $1.302 E+06$ & 4.978 \\
\hline & 46111 & $2.610 E+06$ & 0.279 \\
\hline & 46112 & $7.791 E+03$ & 0.046 \\
\hline \multirow{2}{*}{$\mathrm{Tl}$} & 81202 & $8.069 E+02$ & 0.015 \\
\hline & 81204 & $4.524 E+03$ & 9.756 \\
\hline Mo & 42099 & $1.092 E+06$ & 2.272 \\
\hline $\mathrm{Y}$ & 39090 & $4.296 E+05$ & 0.790 \\
\hline
\end{tabular}


best uniform power density profile is obtained in the thallium case.

(ii) The production of radioisotopes is in the range of $0.192-31.810 \mathrm{~g}$ at the end of one-hour cycle. The case of copper-thulium is the best case $\left[31.810 \mathrm{~g}{ }^{170} \mathrm{Tm}\right.$ $(1.901 E+05 \mathrm{Ci})]$.

(iii) The highest flattened fission power profile is in the copper-holmium case (about $7 \cdot 4 \cdot 10^{-5}$ fissions $/ \mathrm{cm}^{3}$ ).

(iv) The energy gain is in the range of 30.13-72.91. The best energy multiplication is obtained in the case of copper-holmium.

In conclusion, the investigated ADS has a good neutronic performance in terms of energy production, radioisotope production, spent fuel transmutation, and management of nuclear waste.

\section{Competing Interests}

The authors declare that there are no competing interests regarding the publication of this paper.

\section{Acknowledgments}

This study is supported by the Research Fund of Erciyes University, Project no. FDK-2015-5811.

\section{References}

[1] H. A. Abderrahim, "Multi-purpose hybrid research reactor for high-tech applications a multipurpose fast spectrum research reactor," International Journal of Energy Research, vol. 36, no. 15, pp. 1331-1337, 2012.

[2] H. Yapıc1, G. Genç, and N. Demir, "A comprehensive study on neutronics of a lead-bismuth eutectic cooled accelerator-driven sub-critical system for long-lived fission product transmutation," Annals of Nuclear Energy, vol. 35, no. 7, pp. 1264-1273, 2008.

[3] V. N. Starovoitova, L. Tchelidze, and D. P. Wells, "Production of medical radioisotopes with linear accelerators," Applied Radiation and Isotopes, vol. 85, pp. 39-44, 2014.

[4] V. N. Richards, E. Mebrahtu, and S. E. Lapi, "Cyclotron production of ${ }^{99 m} \mathrm{Tc}$ using ${ }^{100} \mathrm{Mo}_{2} \mathrm{C}$ targets," Nuclear Medicine and Biology, vol. 40, pp. 939-945, 2013.

[5] W. D. Webster, G. T. Parks, D. Titov, and P. Beasley, “The production of radionuclides for nuclear medicine from a compact, low-energy accelerator system," Nuclear Medicine and Biology, vol. 41, pp. 7-15, 2014.

[6] K. Abbas, S. Buono, N. Burgio et al., "Development of an accelerator driven neutron activator for medical radioisotope production," Nuclear Instruments and Methods in Physics Research, vol. 601, no. 3, pp. 223-228, 2009.

[7] T. Kin, Y. Nagai, N. Iwamoto et al., "New production routes for medical isotopes ${ }^{64} \mathrm{Cu}$ and ${ }^{67} \mathrm{Cu}$ using accelerator neutrons," Journal of the Physical Society of Japan, vol. 82, no. 3, Article ID 034201, 8 pages, 2013.

[8] F. Tárkányi, S. Takács, A. Hermanne et al., "Investigation of production of the therapeutic radioisotope ${ }^{165} \mathrm{Er}$ by proton
Induced reactions on erbium in comparison with other production routes," Applied Radiation and Isotopes, vol. 67, pp. 243-247, 2009.

[9] F. Tárkányi, A. Hermanne, S. Takács et al., "Investigation of new routes for production of the therapeutic radionuclides ${ }^{169} \mathrm{Yb}$ and ${ }^{165}$ Er," Journal of Labelled Compounds and Radiopharmaceuticals, supplement 50, p. 99, 2007, Proceedings of the 17th International Symposium on Radiopharmaceutical Sciences, Aachen, Germany.

[10] F. Tárkányi, A. Hermanne, S. Takács et al., "Experimental study of the ${ }^{165} \mathrm{Ho}(\mathrm{p}, \mathrm{n})$ nuclear reaction for production of the therapeutic radioisotope ${ }^{165} \mathrm{Er}, "$ Nuclear Instruments and Methods in Physics Research Section B: Beam Interactions with Materials and Atoms, vol. 266, no. 15, pp. 3346-3352, 2008.

[11] F. Tárkányi, A. Hermanne, S. Takács et al., "Experimental study of the ${ }^{165} \mathrm{Ho}(\mathrm{d}, 2 \mathrm{n})$ and ${ }^{165} \mathrm{Ho}(\mathrm{d}, \mathrm{p})$ nuclear reactions up to $20 \mathrm{MeV}$ for production of the therapeutic radioisotopes ${ }^{165}$ Er and ${ }^{1669}$ Ho," Nuclear Instruments and Methods in Physics Research B, vol. 266, no. 16, pp. 3529-3534, 2008.

[12] F. Tárkányi, A. Hermanne, F. Ditrói, S. Takács, R. Adam Rebeles, and A. V. Ignatyuk, "New data on cross-sections of deuteron induced nuclear reactions on gold up to $50 \mathrm{MeV}$ and comparison of production routes of medically relevant $\mathrm{Au}$ and Hg radioisotopes," Nuclear Instruments and Methods in Physics Research, vol. 362, pp. 116-132, 2015.

[13] P. H. Liem, H. N. Tran, and T. M. Sembiring, "Design optimization of a new homogeneous reactor for medical radioisotope Mo-99/Tc-99m production," Progress in Nuclear Energy, vol. 82, pp. 191-196, 2015.

[14] S. G. Lebedev, L. Y. Sosnin, and A. N. Cheltsov, " ${ }^{173}$ Lu and other radioisotopes production possibilities on medium energy linear proton accelerator for their use in radiographic equipment," Nuclear Instruments and Methods in Physics Research Section A: Accelerators, Spectrometers, Detectors and Associated Equipment, vol. 613, no. 3, pp. 477-479, 2010.

[15] O. Artun and H. Aytekin, "Calculation of excitation functions of proton, alpha and deuteron induced reactions for production of medical radioisotopes ${ }^{122--125} \mathrm{I}$," Nuclear Instruments and Methods in Physics Research B, vol. 345, pp. 1-8, 2015.

[16] F. M. Nortier, S. J. Mills, and G. F. Steyn, "Excitation functions for the production of some radioisotopes of Cs, Xe and I in proton bombardment of $\mathrm{Xe}^{\text {nat }}$ up to $100 \mathrm{MeV}$," Applied Radiation and Isotopes, vol. 46, no. 12, pp. 1377-1385, 1995.

[17] Ş. Okuducu, N. N. Akti, and E. Eser, "The theoretical nuclear level density parameters of some deformed target radioisotopes $181-187 \mathrm{~W}$ and $196-204 \mathrm{Hg}$ used on the accelerator-driven systems," Annals of Nuclear Energy, vol. 38, no. 8, pp. 1769-1774, 2011.

[18] H. Yapıc1 and M. Übeyli, "Power flattening in Prometheus breeder reactor using nuclear fuel and waste actinide," Annals of Nuclear Energy, vol. 30, no. 2, pp. 159-173, 2003.

[19] H. Yapıc1, "Power flattening of an inertial fusion energy breeder with mixed $\mathrm{ThO}_{2}-\mathrm{UO}_{2}$ fuel," Fusion Engineering and Design, vol. 65, no. 1, pp. 89-108, 2003.

[20] H. Yap1c1, "Determination of the optimal plutonium fraction in transuranium discharged from pressured water reactor (PWR) spent fuel for a flat fission power generation in the force-free helical reactor (FFHR) along the transmutation period," Annals of Nuclear Energy, vol. 30, no. 6, pp. 633-649, 2003.

[21] H. Ait Abderrahim, J. Galambos, Y. Gohar et al., "Accelerator and target technology for accelerator driven transmutation 
and energy production," White Paper FERMILAB-FN-0907DI, LA-UR-10-06754, Fermilab, 2010.

[22] B. Manson, H. P. Thomas, and W. L. Hans, Nuclear Chemical Engineering, McGraw-Hill, New York, NY, USA, 1981.

[23] D. B. Pelowitz, MCNPX, User's Manual, Version 2.6.0, LA-CP07-1473, 2008.

[24] M. B. Chadwick, P. G. Young, S. Chiba et al., "Cross-section evaluations to $150 \mathrm{MeV}$ for accelerator-driven systems and implementation in MCNPX," Nuclear Science and Engineering, vol. 131, no. 3, pp. 293-328, 1999.

[25] H. W. Bertini, "Low-energy intranuclear cascade calculation," Physical Review, vol. 131, no. 4, pp. 1801-1821, 1963.

[26] H. Yapıc1, G. Genç, and N. Demïr, "Neutronic limits in infinite target mediums driven by high energetic protons," Annals of Nuclear Energy, vol. 34, no. 5, pp. 374-384, 2007. 

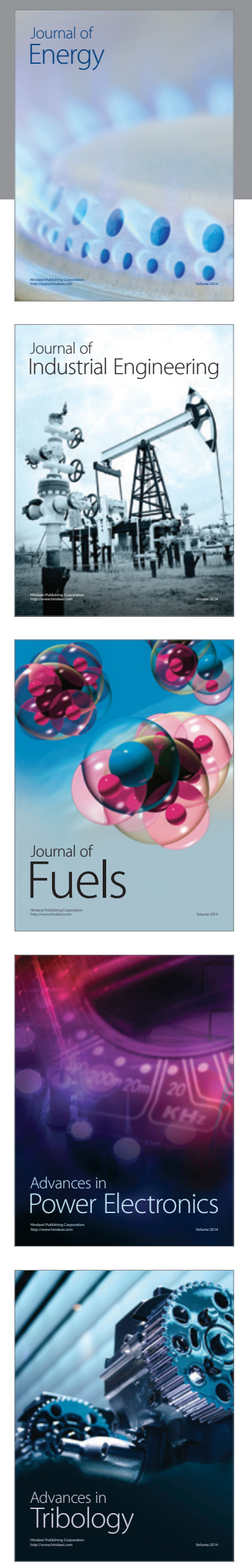


The Scientific World Journal
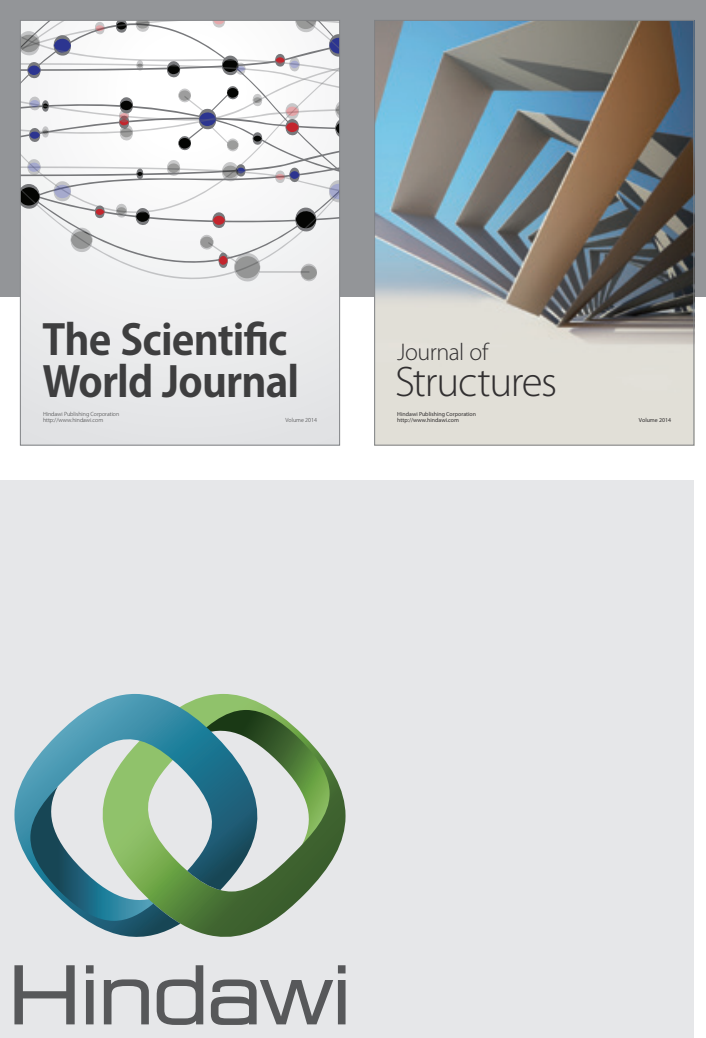

Submit your manuscripts at

http://www.hindawi.com
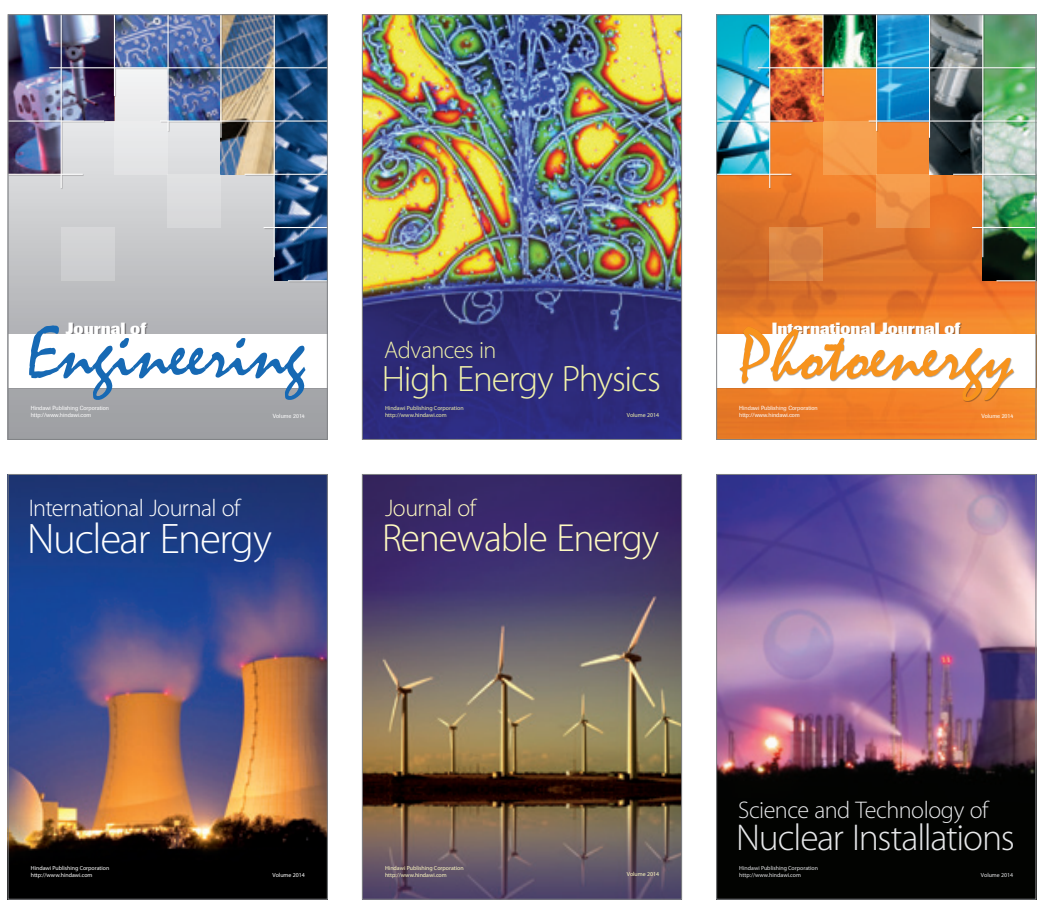
